\title{
In-vitro Cytotoxicity and in silico Molecular Docking of Alkaloids from Tiliacora acuminata
}

\author{
Jeswiny Rodrigues ${ }^{1}$, Kirankumar Hullatti ${ }^{1, \star}$, Sunil Jalalpure ${ }^{1}$, Pukar Khanal $^{2}$ \\ 1'Department of Pharmacognosy, KLE College of Pharmacy, Belagavi, KLE Academy of Higher Education and Research (KAHER), \\ Belagavi, Karnataka, INDIA. \\ ${ }^{2}$ Department of Pharmacology and Toxicology, KLE College of Pharmacy, Belagavi, KLE Academy of Higher Education and Research \\ (KAHER), Belagavi, Karnataka, INDIA.
}

\begin{abstract}
Background: The present study aimed to identify the cytotoxicity of Tiliacora acuminata extract/fraction(s) plant via bioactivity guided approach and predict the binding affinity with Topoisomerase II. Materials and Methods: Extract and fractions were screened using brine shrimp lethality bioassay and the potent fraction was further evaluated for its in vitro cytotoxicity using five different cell lines i.e. HT-29, HepG2, MCF-7 and A-549. The binding affinity of individual phytoconstituent from the potent fraction with Topoisomerase II was further predicted using autodock4. Results: The fraction containing alkaloids showed the highest cytotoxicity against the HT-29 cell line. Molecular docking study identified coclaurine as a potent alkaloid phytoconstituent to bind with topoisomerase II. Conclusion: The study revealed the potential cytotoxic alkaloids from $T$. acuminata which may find use in the development of cytotoxic or chemopreventive agents.
\end{abstract}

Key words: Alkaloids, Brine shrimp, Docking, Menispermaceae, MTT, Topoisomerase II.

\section{INTRODUCTION}

Cancer has emerged as a severe health issue worldwide, increasing at an alarming rate and it was responsible for 8.8 million deaths in 2015. ${ }^{1}$ The primary abnormality that drives the development of cancer is the continuous unregulated proliferation of cancer cells, which invade normal tissues and eventually spread throughout the body; due to mutations leading to genetic alterations and abnormal proliferation of single-cell. ${ }^{2}$

Primarily, the current cancer therapy includes surgery, radiation and chemotherapy. Due to toxicity and contraindications associated with current drugs and limited selectivity towards cancer cells, the search for newer agents for cancer management and treatment is of great interest. ${ }^{3}$ This necessitates the design and development of novel anticancer drugs or combinations in cancer biology. Targeted cancer therapy has come to attain great attention with a number of molecular targets being identified; opens door to potential treatment options for cancer pharmacotherapy. Topoisomerase II, a] catalyst in the cleavage and rejoining of double-stranded DNA is one such molecular target for the development of novel anticancer agents. ${ }^{4}$

Traditional medicine around the globe has utilized natural products as therapeutic agents since ancient times. The Indian traditional system of medicine itself offers a number of plants useful in the treatment of different conditions associated with cancer such as hard swellings, abscesses and inflammation. ${ }^{5}$ The evaluation of their therapeutic efficacy may be useful in modern drug development. The chemotherapeutic properties of many phytochemicals have been well established in recent times. Currently, more than $60 \%$ of drugs used in therapy have been derived from natural sources. ${ }^{6}$ The phytochemicals present in plants possess structural diversity that makes them a unique source in drug development. With the use of simple yet reliable
Submission Date: 14-11-2019; Revision Date: 06-02-2020; Accepted Date: 12-03-2020

DOI: $10.5530 / i j p e r .54 .2 s .86$ Correspondence: Dr. Kirankumar Hullatti Department of Pharmacognosy, KLE College of Pharmacy, KAHER, Belagavi-590010, Karnataka, INDIA.

Phone: +91-9448800184

E-mail: kkhullatti@gmail.com

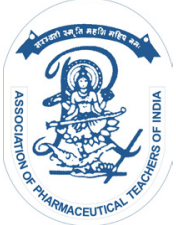

www.ijper.org 
pre-screening models such as the brine shrimp lethality assay, medicinal plants can be effectively screened for their cytotoxic potentials.

Tiliacora acuminata (Lam.) belonging to the family Menispermaceae is a large woody climber. It is mentioned in Ayurvedic medicine as Krishnavetra which alleviates many ailments and cures cancerous diseases. ${ }^{8,9}$ It is also traditionally used as an antidote to treat snake bites. ${ }^{10}$ The root of $T$. acuminata contains a number of bisbenzylisoquinoline alkaloids and the cytotoxic activity of the root extract has been reported previously. ${ }^{11}$ However; investigations on the active compounds are still in progress. Hence the present study aims to evaluate T. acuminata for in vitro cytotoxicity and in silico molecular docking.

\section{MATERIALS AND METHODS}

\section{Collection of plant material}

The whole plant of $T$. acuminata was collected from the wild regions of Tirupati, Eastern Ghats, Andhra Pradesh, authenticated by Botanist, Dr. K. Madhava Chetty at Sri. Venkateswara University, Tirupati, Andhra Pradesh and herbarium of the same was deposited with voucher number 0948.

\section{Preparation of extracts and fractions}

The extraction and fractionation were carried out according to the generic scheme described by Cos et al..$^{12}$ with minor modifications. The coarsely powdered material was subjected to maceration using $70 \%$ ethanol for 24 hrs. After filtration, the marc was dried and subjected to soxhlet extraction using ethanol as solvent. The macerate and percolate were then combined and concentrated using a rotary evaporator (IKA-RV Digital) to obtain the final extract. Fractionations of ethanol extract yielded methanol, petroleum ether, dichloromethane and aqueous fractions (Figure 1).

\section{Brine shrimp Lethality (BSL) Bioassay}

The brine shrimp (Artemia salina Leach.) eggs (Seamonk international Artemia cyst 003) were used for the assay. The bioassay was carried out according to the method described by McLaughlin et al..$^{13}$ with modifications. Stock solutions $(5000 \mu \mathrm{g} / \mathrm{ml})$ of extracts/fractions were prepared in 1\% DMSO and serial dilutions in geometric progression were made using seawater. Ten shrimps were exposed to $5 \mathrm{ml}$ of each test solution. Control tubes contained equal volumes of distilled water. The assay was carried out in triplicate for each concentration. At the end of $24 \mathrm{hr}$, the number of survivors was

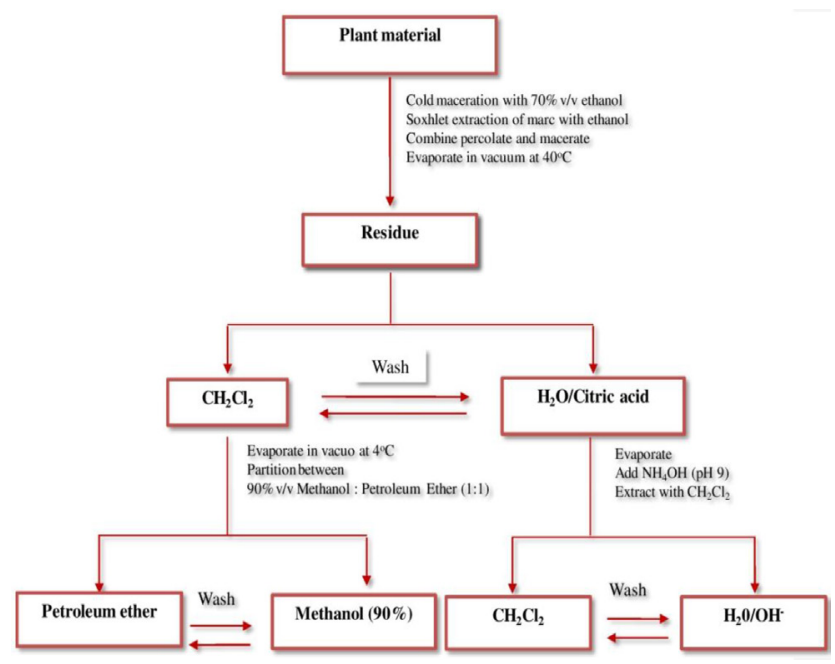

Figure 1: Scheme of extraction and fraction of T. acuminata.

counted and $\mathrm{LC}_{50}$ values were calculated by probit analysis.

\section{Cell culture}

The cell lines A-549 (Human, small cell lung carcinoma), MCF-7 (Human, breast cancer), HepG-2 (Human, hepatic cancer), HT-29 (Human, colon cancer) and L-6 (Rat, normal skeletal muscle) were procured from National Centre for Cell Sciences, Pune, India. Stock cells were cultured and grown in $25 \mathrm{~cm}^{2}$ culture flasks (Tarsons India Pvt. Ltd, Kolkata, India) using Dulbecco's Modified Eagle Medium (DMEM) supplemented with $10 \%$ inactivated fetal bovine serum (FBS), penicillin $(100 \mathrm{IU} / \mathrm{ml})$, streptomycin $(100 \mathrm{mg} / \mathrm{ml})$ and amphotericin $\mathrm{B}(5 \mathrm{mg} / \mathrm{ml})$ in an humidified atmosphere of $5 \% \mathrm{CO}_{2}$ at $37^{\circ} \mathrm{C}$ until confluent. The cells were detached with trypsin phosphate versene glucose solution ( $0.2 \%$ trypsin, $0.02 \%$ EDTA, $0.05 \%$ glucose in PBS).

\section{MTT Assay for cytotoxicity}

The bioactive fractions from brine shrimp bioassay were screened for cytotoxicity by 3-(4,5-dimethylthiazol-2yl)-2,5-diphenyltetrazolium bromide (MTT) assay. ${ }^{14}$ Briefly, cell monolayers were trypsinized, washed with culture medium and plated in 96-well microtiter plates and incubated for $24 \mathrm{hr}$. Each dilution of fraction 3 was added to the wells and plates were incubated for $48 \mathrm{hr}$ in a humidified incubator at $37^{\circ} \mathrm{C}$ with $5 \% \mathrm{CO}_{2}$. After incubation, $10 \mu \mathrm{l}$ of MTT $(5 \mathrm{mg} / \mathrm{ml}$ in PBS) was added to each well and incubated again for $4 \mathrm{hr}$. The absorbance was measured using a microplate reader at a wavelength of $540 \mathrm{~nm}$.

\section{Molecular docking}

Docking of phytoconstituents with topoisomerase II was performed as previously explained by Khanal et 
al..$^{15}$ Briefly, the selected ligand molecules i.e. coclaurine, magnoflorine and stepholidine were retrieved from the PubChem database in. sdf format and converted into.pdb using discovery studio 2017; minimized using mmff94 force field and conjugate gradients as an optimization algorithm. After minimization, the pose scoring the minimum binding energy was chosen as a ligand molecule for docking. Topoisomerase II (PDB ID: 4GHF) was retrieved from the RCSB database; used as a template for query sequence for accession number: P11388.3 for homology modeling by adding the missing amino acid using Modeller 9.10. The retrieved protein molecule contained the water molecules and other heteroatoms; removed using Discovery Studio 2017; avoids docking interference and saved in .pdb format and docking was carried by using autodock4.0 under Lamarckian GA 4.2. After docking the pose scoring minimum binding energy was chosen to visualize the ligand-protein interaction using Discovery Studio 2017.

\section{Statistical analysis}

Data were expressed as Mean \pm SD using Graph Pad Prism version 5.0. All experiments were performed in triplicates. $\mathrm{IC}_{50}$ was calculated using a linear regression curve and lethal concentration $\left(\mathrm{LC}_{50}\right)$ was calculated probit analysis. The binding affinity of compounds was represented as binding energy.

\section{RESULTS AND DISCUSSION \\ BSL bioassay of extract and fractions}

The extract of $T$. acuminata showed promising toxicity towards brine shrimps with $\mathrm{LC}_{50}$ of $51.299 \pm 3.16 \mu \mathrm{g} / \mathrm{ml}$. Fractions 3 showed the most cytotoxicity with $\mathrm{LC}_{50}$ of $45.57 \pm 2.14 \mu \mathrm{g} / \mathrm{ml}$; summarized in Table 1. The other fractions showed moderate to no activity in the BSL bioassay.

\section{MTT Assay of the fraction}

The fraction 3 showed the highest cytotoxicity against HT-29 $\left(\mathrm{IC}_{50}=79.52 \pm 1.21 \mu \mathrm{g} / \mathrm{ml}\right)$ compared to the other cell lines A-549 $(127 \pm 6.44 \mu \mathrm{g} / \mathrm{ml})$ and Hep G-2 $(185.1 \pm 8.16 \mu \mathrm{g} / \mathrm{ml})$. Percentage cell growth inhibition was observed in a concentration-dependent manner and summarised in Figure 2. Fractions did not show cytotoxicity towards the MCF-7 cell line. The fraction was also found to be non-cytotoxic to normal cells displaying more than $70 \%$ cell viability at all the concentrations in the L6 normal cell line.

\section{Molecular docking}

Three phytoconstituents caclaurine, magnoflorine and stepholidine; previously reported in T. acuminata were studied by molecular docking for their binding affinity with topoisomerase II. Coclaurine was predicted for the highest binding affinity with topoisomerase II with a maximum number of $\mathrm{H}$-bond interactions.

Stepholidine was found to show the least binding affinity with topoisomerase II. The binding energy, inhibitory coefficient and $\mathrm{H}$-bond interactions of individual phytoconstituents with topoisomerase II are summarized in Table 2. The interaction of individual compounds with topoisomerase II is shown in Figure 3.

Table 1: Lethal concentration $\left(\mathrm{LC}_{50}\right)$ of extract/fractions of $T$. acuminata in BSL Bioassay.

\begin{tabular}{|c|c|}
\hline Extract / Fractions & LC $_{50}(\mathbf{p p m})$ \\
\hline T. acuminata hydroalcoholic extract & $51.299 \pm 1.13$ \\
\hline Fraction 1 & $83.28 \pm 1.35$ \\
\hline Fraction 2 & $332.7 \pm 2.26$ \\
\hline Fraction 3 & $45.57 \pm 1.56$ \\
\hline Fraction 4 & $395.22 \pm 1.19$ \\
\hline
\end{tabular}

Values are expressed as Mean \pm SEM

\begin{tabular}{|c|c|c|c|}
\hline \multirow[t]{2}{*}{ Phytoconstituents } & \multicolumn{3}{|c|}{ Topoisomerase II (PDB: 4GHF) } \\
\hline & $\begin{array}{c}\text { BE } \\
\text { (kcal/ } \\
\text { mol) }\end{array}$ & $\mathrm{IC}_{50}(\mu \mathrm{M})$ & $\begin{array}{l}\text { Interacting Hydrogen } \\
\text { Bond Residues }\end{array}$ \\
\hline Coclaurine & -5.29 & 133.53 & $\begin{array}{c}\text { ASP } 479, \text { ASP } 446, \\
\text { ARG } 450, \text { GLU 454, } \\
\text { LYS } 480\end{array}$ \\
\hline Magnoflorine & -5.21 & 150.75 & LEU 473, GLY 474, \\
\hline Stepholidine & -4.48 & 520.33 & SER 709 \\
\hline
\end{tabular}

$\mathrm{BE}$ : Binding Energy, IC $\mathrm{I}_{50}$ : Inhibitory Concentration 50

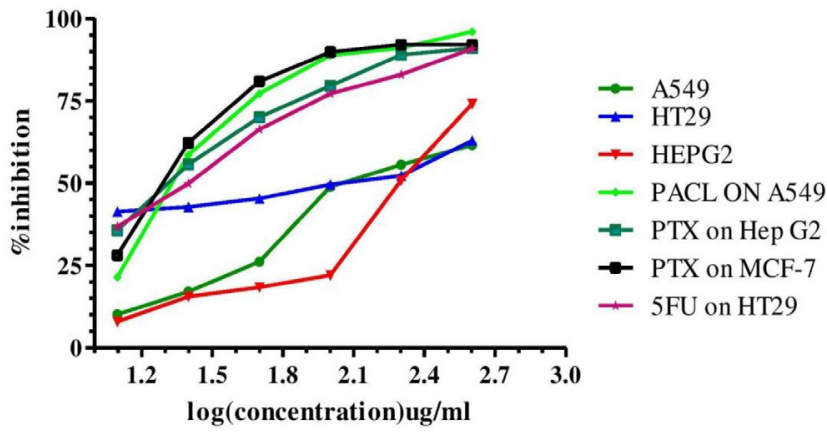

Figure 2: Percentage inhibition of cell growth of $T$. acuminata fraction 3 on various cell lines. Values are expressed as Mean \pm SEM $(n=3)$. 


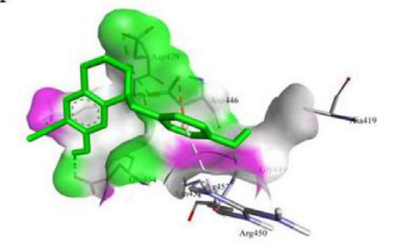

B

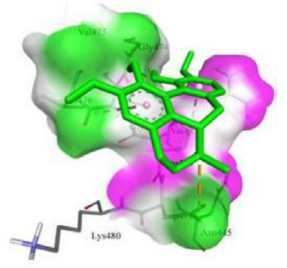

C

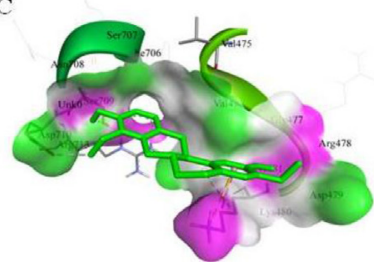

Figure 3: Interaction of (a) Caclaurine, (b) Magnoflorine, (c) Stepholidine.

The present study aimed to identify potential phytoconstituents from $T$. acuminata with special reference to cytotoxicity using in vitro and in silico approach. To deal with this approach, BSL bioassay and MTT cytotoxicity assay were performed which identified alkaloid fraction as a promising group of phytoconstituents. Initially, BSL bioassay was performed to pre-screen the fractions to narrow down the active fraction from $T$. acuminata extract. This bioassay has been successful in the identification of many bioactive components from natural sources including cytotoxic constituents. ${ }^{16,17}$ Compounds with $\mathrm{LC}_{50}$ lower than $100 \mu \mathrm{g} / \mathrm{ml}$ may be considered as cytotoxic. ${ }^{18}$ The lethality to brine shrimps has been frequently reported as a reliable pre-screening assay to the existing cytotoxicity assays. ${ }^{19}$ Thus, rapid screening of extracts and fractions for potential cytotoxicity can be obtained by this assay.

In the present study, a fraction rich in alkaloids showed the highest toxicity to brine shrimps. The methanolic fraction 1, petroleum ether fraction 2 and aqueous fraction 4 did not show promising cytotoxicity in the BSL bioassay. Hence alkaloidal fraction of $T$. acuminata was taken assessed for in vitro cytotoxicity studies using a panel of cell lines. The ability of the fraction to inhibit cell growth was determined by reduction in the MT'T dye to soluble formazan crystals by metabolically active mitochondrial enzymes. ${ }^{20}$ The alkaloidal fraction showed the cytotoxicity in HEPG2 and HT29, however, the highest cytotoxic potency was towards the HT-29 cell line. Diphenylbisbenzylisoquinoline alkaloids have been identified as the principal components in T. acuminata. ${ }^{21}$ The cytotoxic activity of $T$. racemosa has been previously reported in acute myeloblastic leukemia (HL-60), chronic myeloblastic leukemia (K-562) and cervical epithelial carcinoma (HeLa) tumor cell lines. ${ }^{22}$
Tiliarine has previously shown in vitro inhibition of human melanoma cells. ${ }^{23}$

Targeting topoisomerase II is a well-accepted approach in cancer chemotherapy by inhibiting the enzymemediated DNA damage. Topoisomerase II enzyme is of vital use in cell processes namely, replication, transcription, chromosome separation and segregation since it acts as a catalyst in the cleavage and rejoining of double-stranded DNA. Topoisomerase II is reported to be highly overexpressed in proliferating cancer cells and hence makes it a potential target for new anticancer drugs. ${ }^{24}$ Further, previous docking studies also report the interaction of multiple phytoconstituents with various protein molecules. ${ }^{15,25}$ Hence, we investigated the binding affinity of reported alkaloids from T. acuminata with topoisomerase II. Nine different alkaloids i.e. coclaurine, coreximine, isoboldine, liridenine, magnoflorine, norjuziphine, nortrilobine, stepholidine and trilobine were investigated to predict the binding affinity and possible phytoconstituent-topoisomerase II interaction using in silico molecular docking. Interestingly, we identified coclaurine to have the highest binding affinity by interacting with ASP 479, ASP 446, ARG 450, GLU 454, LYS 480 amino acid residues (Table 2). The present study is also supported by the anti-cancer activity of coclaurine on various cell line studies. ${ }^{26}$ Further, previous studies suggest that a lead molecule can target multiple proteins and regulate the multiple pathways in a particular disease $\mathrm{e}^{27,28}$ which is the future scope of the study to evaluate the role of hit molecules in cancer treatment. Further, a single compound can modulate multiple protein/pathway $(\mathrm{s})^{29}$ which can be further evaluated for Coclaurine via gene set enrichment analysis with special reference to the pathways involved in cancer pathogenesis.

\section{CONCLUSION}

The present study utilized bioactivity guided screening of hydroalcoholic extract/fraction(s) of Tiliacora acuminata which identified fraction rich in alkaloids to be a potent agent against multiple cell lines. Additionally, coclaurine was predicted to have the highest binding affinity with Topoisomerase II which needs to be further confirmed via in vitro enzyme assay. Additionally, we suggest performing a coclaurine-modulated gene set enrichment analysis with special reference to protein/ pathway(s) involved in cancer pathogenesis.

\section{ACKNOWLEDGEMENT}

The authors are thankful to Principal, KLE College of Pharmacy, Belagavi and KLE's Dr. Prabhakar Kore 
Basic Science Research Centre, Belagavi for providing necessary facilities for carrying out the work.

\section{CONFLICT OF INTEREST}

The authors declare no conflict of interest.

\section{ABBREVIATIONS}

BSL: Brine Shrimp Lethality, MTT: 3-(4,5-dime thyl thiazol-2-yl)-2,5-diphenyl tetrazolium bromide; PDB: Protein Data Bank, RCSB: Research Collaboratory for Structural Bioinformatics, IC $_{50}$ : Inhibitory concentration $50, \mathbf{L C}_{50}$ : Lethal concentration 50.

\section{REFERENCES}

1. World health organisation media centre-Worldwide Cancer statistics. Internet. 2018. cited 2018 Nov 14Available from: http://www.who.int/mediacentre/ factsheets/fs297/en/.

2. Cooper GM. The Cell: A Molecular Approach, $2^{\text {nd }}$ ed. Sinauer Associates: Sunderland (MA), 2000.

3. Gibbs JB. Mechanism-based target identification and drug discovery in cancer research. Science. 2000;287(5460):1969-73.

4. Nitiss JL. Targeting DNA topoisomerase II in cancer chemotherapy. Nat Rev Cancer. 2009;9(5):338-50

5. Petrovska BB. Historical review of medicinal plants' usage. Pharmacogn Rev. 2012;6(11):1-5.

6. Cragg GM, Newman DJ. Plants as a source of anti-cancer agents. J Ethnopharmacol. 2005;100(1-2):72-9.

7. Meyer BN, Ferrigni JE, Putnam JE, Jacobson LB, Nicholas DE, McLaughlin JL. Brine shrimp: A convenient general bioassay for active plant constituents. Planta Med. 2005;45(05):31-4.

8. Sharma PV. In Cakradatta (A Treatise of Principles and Practices of Ayurvedic Medicine). Varanasi: Chaukhamba Orientalia. 1994.

9. Murthy KR. In Astanga Hridayam, Varanasi: Krishnadas Academy. 1995;2:464.

10. Sri BS, Reddi TW. Traditional phyto-antidotes used for snakebite by Bagata tribe of Eastern Ghats of Visakhapatnam district, Andhra Pradesh. Int Multidiscip Res J 2011;1(6):42-5.

11. Chakraborty S, Roy M, Taraphdar AK, Bhattacharya RK. Cytotoxic Effect of Root Extract of Tiliacora racemosa and Oil of Semecarpus anacardium Nut in Human Tumour Cells. Phytother Res. 2004;18(8):595-600.
12. Cos P, Vlietinck AJ, Berghe DV, Maes L. Anti-infective potential of natural products: How to develop a stronger in vitro proof-of-concept. J Ethnopharmacol. 2006;106(3):290-302.

13. McLaughlin J, Rogers LL. The use of biological assays to evaluate botanicals. Drug Inf J. 1998;32(2):513-24.

14. Mosmann T. Rapid colorimetric assay for cellular growth and survival: Application to proliferation and cytotoxicity assays. J Immunol Meth. 1983;65(1-2):55-63.

15. Khanal P, Mandar BK, Patil BM, Hullatti KK. In silico Antidiabetic Screening of Borapetoside C, Cordifolioside A and Magnoflorine. Indian J Pharm Sci. 2019;81(3):550-5.

16. Karchesy YM, Kelsey RG, Constantine G, Karchesy JJ. Biological screening of selected Pacific Northwest forest plants using the brine shrimp (Artemia salina) toxicity bioassay. Springer Plus. 2016;5(1):510.

17. Ludwiczuk A, Saha A, Kuzuhara T, Asakawa Y. Bioactivity guided isolation of anticancer constituents from leaves of Alnussie boldiana (Betulaceae). Phytomedicine. 2011;18(6):491-8.

18. Pimentel MAB, Pizzolatti MG, Costa BIM. An application of the brine shrimp bioassay for general screening of brazilian medicinal plants. Acta Farm Bonaerense. 2002;21(3):175-8.

19. Anderson JE, Goetz CM, McLaughlin JL, Suffness M. A blind comparison of simple bench-top bioassays and human tumour cell cytotoxicitis as antitumor pre-screens. Phytochem Anal. 1991;2(3):107-11.

20. Senthilraja P, Kathiresan K. In vitro cytotoxicity MTT assay in Vero, HepG2 and MCF-7 cell lines study of marine yeast. J App Pharm Sci. 2015;5(3):80-4.

21. Anjaneyulu B, Govindachari TR, Sathe SS, Viswanathan N, Gopinath KW, Pai BR. Alkaloids of Tiliacora racemosa Colebr. Tetrahedron. 1969;25(15):3091-105.

22. Sutapa C, Madhumita R, Amit KT, Bhattacharya RK. Cytotoxic effect of root extract of Tiliacora racemosa and oil of Semecarpus anacardium nut in human tumour cells. Phytother. Res. 2004;18(8):595-600.

23. Seal T, Mukherjee B. (+)-Tiliarine, a selective in vitro inhibitor of human melanoma cells. Phytother Res. 2002;16(6):596-9.

24. Sangpheak K, Mueller M, Darai N, Peter WC, Suwattanasophon C, Ruga R, et al. Computational screening of chalcones acting against topoisomerase lla and theircytotoxicity towards cancer cell lines. J Enzyme Inhib Med Chem. 2019;34(1):134-43.

25. Khanal P, Mandar BK, Magadum P, Patil BM, Hullatti KK. In silico docking study of Limonoids from Azadirachta indica with pfpk 5: A Novel Target for Plasmodium falciparum. Indian J Pharm Sci. 2019;81(2):326-32

26. Al-ghazzawi AM. Anti-cancer activity of new benzyl isoquinoline alkaloid from Saudi plant Annona squamosa. BMC Chem. 2019;13(1):13

27. Khanal P, Patil BM. Gene set enrichment analysis of alpha-glucosidase inhibitors from Ficus benghalensis. Asian Pac J Trop Biomed. 2019;9(6):263-70.

28. Khanal P, Patil BM, Mandar BK, Dey YN, Duyu T. Network pharmacologybased assessment to elucidate the molecular mechanism of anti-diabetic action of Tinospora cordifolia. Clin Phytosci. 2019;5(1):35.

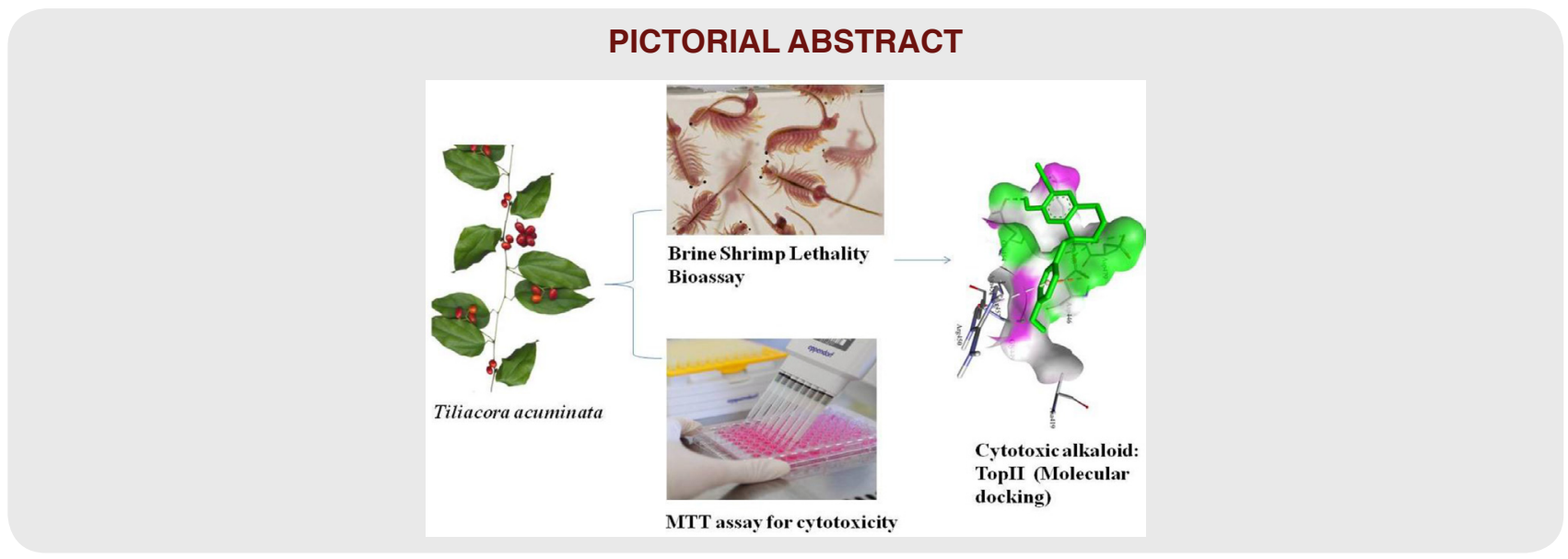




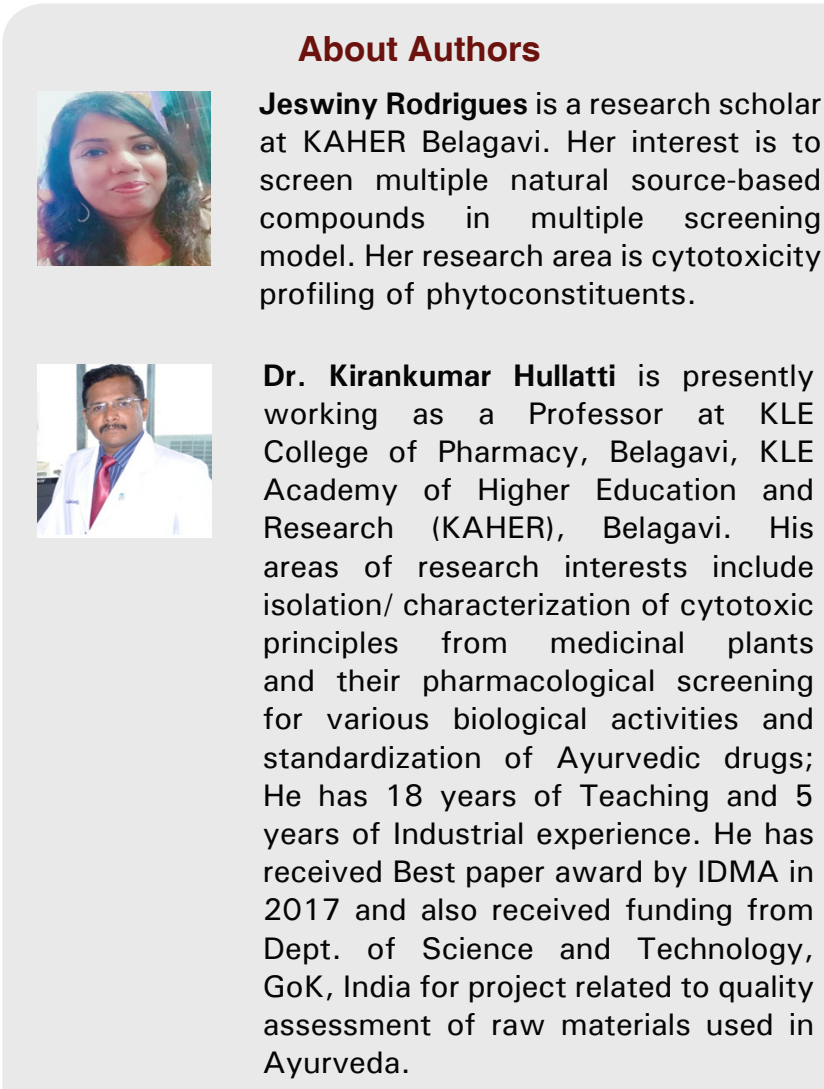

\section{SUMMARY}

Cancer is one of the leading causes of death all over the world. The shortcomings in current drugs used in chemotherapy necessitate the discovery and development of newer drugs. Plants have long been associated with treatment in various forms and even today are recognized as important reservoirs for molecular leads. The current study evaluated the cytotoxic potential of $T$. acuminata using the bioactivity guided approach. The BSL the bioassay was used as a pre-screening model to rule out the least/inactive fractions. According to this assay, the alkaloid fraction showed the highest cytotoxicity and hence was further evaluated using a panel of human cancer cell lines. The alkaloid fraction showed the most cytotoxicity against the HT-29 cell line. Thus, nine alkaloids previously reported from $T$. acuminata were evaluated for their binding affinity with topoisomerase II enzyme using molecular docking. This enzyme plays a major role in vital cell processes. Caclaurine was found to show the highest binding affinity with topoisomerase II. Thus, the study revealed the presence of cytotoxic constituents from $T$. acuminata which may further be evaluated thoroughly. The study forms the base for the development of potential anticancer molecules from T. acuminata.

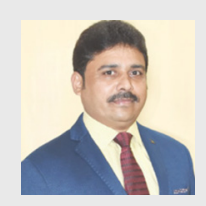

Dr. Sunil S. Jalalpure is presently working as a Principal and Professor at KLE College of Pharmacy, Belagavi, KLE Academy of Higher Education and Research (KAHER), Belagavi. His areas of research interests include isolation/ characterization of active principles from medicinal plants and their pharmacological screening for various biological activities and training the research students in Pharmacognosy, Phytochemistry and Biotechnological aspects with modern tools and techniques. He is recently involved in nanoparticle drug delivery system of herbal actives and green nanotechnology.

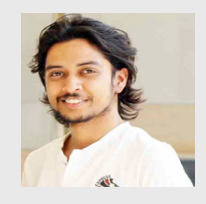

Pukar Khanal has been awarded the gold medal twice for his academic performance. His area of interest covers network pharmacology, ADMET profiling of lead hits from a natural source and their pharmacological evaluation, gene set enrichment analysis, prediction and assessment of protein-protein network interaction, in silico molecular docking, protein modeling and utilizing Danio rerio as a preliminary animal model. Further, he interests to utilize regression models for the evaluation of PKPD profiles and data correlation with wet-lab protocols.

Cite this article: Rodrigues J, Hullatti K, Jalalpure SS, Khanal P. In-vitro Cytotoxicity and in silico Molecular Docking of Alkaloids from Tiliacora acuminata. Indian J of Pharmaceutical Education and Research. 2020;54(2s):s295-s300. 